\title{
Urethral Cancer cM0 TNM Finding v8
}

National Cancer Institute

\section{Source}

National Cancer Institute. Urethral Cancer CMO TNM Finding v8. NCI Thesaurus. Code C140431.

Urethral cancer without evidence of distant metastasis. (from AJCC 8th Ed.) 